\title{
ENZYMIC OXIDATION AND REDUCTION OF CORTISOL WITH BACILLUS CEREUS
}

\author{
ABDEL-MONEM EL-REFAI, LOTFY SALLAM, AND NADIA NAIM \\ Microbiological Chemistry Research Laboratory, \\ National Research Centre, Dokki, Cairo, Egypt
}

(Received June 25, 1975)

The enzymatic transformation of cortisol with Bacillus cereus was examined in the presence of some redox agents and enzyme inhibitors. At the early phases of fermentation, the enzymic 1,2-dehydrogenation reaction of cortisol was highly accelerated in the presence of oxidized glutathione. Thereafter, the enzymic reduction of the 20-keto group of cortisol and prednisolone was noticeably enhanced. In the presence of reduced glutathione, prednisolone was quantitatively converted to the $20 \beta$-hydroxy derivative. The bioconversion of cortisol to prednisolone, $20 \beta$-hydroxycortisol, and 20 $\beta$-hydroxyprednisolone was also activated in the presence of azide and cyanide. With iodoacetate, the 1,2-dehydrogenation reaction was promoted while the 20 -keto reduction was markedly repressed.

Pretreatment of the bacterial cells with various $C_{19}$ and $C_{21}$ steroids as well as with cholesterol affected the transformation pattern in different manners. The 1,2-dehydrogenation reaction of cortisol was considerably induced when the cells were pretreated with $\Delta^{1}$-dehydroprogesterone, $\Delta^{1,4}$-androstadienedione, and $\Delta^{1}$-dehydrotestosterone.

The enzymic 1,2-dehydrogenation of steroids, particularly of cortisol, can be cited as one of the most important microbial modification of the steroid ring. The $\Delta^{1}$-dehydro derivative of cortisol, namely, prednisolone, was found to be more potent than the parent 1,2-dihydro compound by a variety of criteria (1). The achievement of this important microbial transformation has been actively pursued for several years $(2,3)$. Some insight has recently been obtained into the mechanism of the enzymic dehydrogenation of steroids $(4,5)$.

In a previous work (6), we examined a variety of bacterial cultures for the performance of 1,2-dehydrogenation of cortisol. A culture of Bacillus cereus isolated from local habitat was selected as the most active organism. Studies 
on some biochemical aspects of transformation of cortisol with this organism were carried out. This includes the investigation of the role of some elements (7) and cofactors (8). Besides formation of prednisolone, reduction of the 20-keto group of cortisol to $20 \beta$-hydroxy group occurred under all conditions.

This paper presents a report of the role of some redox agents as well as some activators and inhibitors on the enzymic transformation of cortisol with $B$. cereus.

\section{MATERIALS AND METHODS}

Cultivation. The local strain of $B$. cereus was supplied from the centre of cultures of this laboratory. The cultivation was made in 250-ml Erlenmeyer flasks, each containing $50 \mathrm{ml}$ of the culture medium composed of glucose 40.0, and peptone 10.0 (g/liter). This medium, which is referred to as "basal-control medium," was modified in a different manner and the $\mathrm{pH}$ value was always adjusted to 7.0. The flasks were sterilized by autoclaving for $20 \mathrm{~min}$ at a pressure of $15 \mathrm{lb} / \mathrm{in}^{2}$ to raise the temperature to $121^{\circ}$ and inoculated with $2 \mathrm{ml}$ of cell suspension of 48hr-old culture of the pure organism. The culture flasks were agitated on a reciprocal shaker (110 strokes $/ \mathrm{min}$; amplitude $7 \mathrm{~cm}$ ) at $30^{\circ}$ for $24 \mathrm{hr}$. Thereafter, $5 \mathrm{mg}$ of cortisol dissolved in $1 \mathrm{ml}$ ethanol was added to each flask and fermentation continued for the required period.

Extraction. At the end of the transformation period, the contents of each flask were homogenized in a blender $(16,000 \mathrm{rpm})$ with 2 volumes of $\mathrm{CHCl}_{3}$ $(100 \mathrm{ml})$. The extraction was repeated three times in order to assure that all the transformation products were extracted. The combined chloroform extracts were washed with a half volume of $5 \% \mathrm{NaHCO}_{3}$ solution followed by an equal volume of distilled water, dried over anhydrous $\mathrm{Na}_{2} \mathrm{SO}_{4}$, filtered, and then concentrated by distillation to give a semi-solid residue (test material).

Analysis. The test material was dissolved in a measured volume of chloroform: methanol $(1: 1, \mathrm{v} / \mathrm{v})$, and analysed thin-layer chromatography on silica gel $\mathrm{G}$ plates (9). To separate the different products on the plate, the following two solvent systems were found to be suitable: (a) Chloroform: cyclohexane: isopropanol $(5: 2: 2, \mathrm{v} / \mathrm{v})$, (b) chloroform: acetone: ethanol $(40: 10: 0.7, \mathrm{v} / \mathrm{v})$. The transformation products as well as cortisol were identified by comparison of the thinlayer chromatographic pattern with that of the authentic steroids using appropriate colour reagents $(10)$.

Quantitative estimation of the products was made by the preparative thin-layer chromatography. A measured volume of the test material was applied as a streak across the bottom of glass plates $(20 \times 20 \mathrm{~cm})$ covered with a layer of silica gel $\mathrm{G}$ (1 $\mathrm{mm}$ in thickness). After development of the plates, the bands of the individual steroids were marked, scraped from the plates, and quantitatively eluted with spectroscopic ethanol. The concentration of each compound was then determined by colorimetry (11). The experiments were carried out in triplicates and the 
results of this work are the arithmetic mean of these replicates.

\section{RESULTS}

The role of some redox agents

It is evident that the addition of Safranin $\mathrm{T}$ to the basal medium caused no effect on the transformation process (Table 1). However, glutathione, potassium ferricyanide, 2,6-dichlorophenol-indophenol, 8-hydroxyquinoline, and Methylene Blue activated the 1,2-dehydrogenation reaction of cortisol. A maximum yield of prednisolone was achieved with glutathione.

Table 1. Transformation of cortisol $(5,000 \mu \mathrm{g} / 50 \mathrm{ml}$ medium) with $B$. cereus as influenced by the addition of redox agents.

\begin{tabular}{lcccc}
\hline \multirow{2}{*}{ Conditions } & \multicolumn{4}{c}{ Transformation mixture $(\mu \mathrm{g} /$ culture) } \\
\cline { 2 - 5 } & $\begin{array}{c}\text { Residual } \\
\text { cortisol }\end{array}$ & $\begin{array}{c}\text { Predni- } \\
\text { solone }\end{array}$ & $\begin{array}{c}20 \beta \text {-Hydroxy- } \\
\text { cortisol }\end{array}$ & $\begin{array}{c}\text { 20 } \beta \text {-Hydroxy- } \\
\text { prednisolone }\end{array}$ \\
\hline Basal medium (control) & 3,479 & 939 & 398 & - \\
Safranin T & 3,502 & 941 & 383 & - \\
Methylene Blue & 3,303 & 1,140 & 437 & - \\
Potassium ferricyanide & 2,411 & 2,067 & 411 & - \\
Glutathione (oxidized form) & 2,255 & 2,360 & 121 & 116 \\
8-Hydroxyquinoline & 3,250 & 1,236 & 391 & - \\
2,6-Dichlorophenol-indophenol & 3,282 & 1,365 & 403 & - \\
\hline
\end{tabular}

The tested redox agents $(3 \mathrm{mg} / 50 \mathrm{ml}$ medium) were individually added to the basal medium at the time of cortical addition.

$-=$ absent

Transformation period: $24 \mathrm{hr}$.

The formation of $20 \beta$-hydroxycortisol was slightly accelerated with most of the tested redox agents except glutathione. In the case of glutathione, an additional product, namely $20 \beta$-hydroxyprednisolone, was formed together with prednisolone and $20 \beta$-hydroxycortisol.

\section{Convertibility of cortisol in the presence of glutathione}

The results of this study (Table 2) revealed that the $\Delta^{1}$-dehydrogenation reaction is the only type of transformation carried out by the experimental organism during the first $24 \mathrm{hr}$ of fermentation. Thus, during that phase of the transformation process, there is an initial lag before the formation of both $20 \beta$-hydroxycortisol and 20 $\beta$-hydroxyprednisolone becomes clear. A subsequent increase of the yield of these hydroxylated products together with a corresponding decrease in the amounts of cortisol and prednisolone was observed between 24 to $48 \mathrm{hr}$ of fermentation. 
Table 2. Transformation of cortisol $(5,000 \mu \mathrm{g} / 50 \mathrm{ml}$ medium) with $B$. cereus in the presence of glutathione (oxidized form) ( $3 \mathrm{mg} / 50 \mathrm{ml}$ medium).

\begin{tabular}{ccccc}
\hline $\begin{array}{c}\text { Transformation } \\
\text { period }\end{array}$ & \multicolumn{4}{c}{ Transformation mixture $(\mu \mathrm{g} /$ culture $)$} \\
\cline { 2 - 5 }$(\mathrm{hr})$ & $\begin{array}{c}\text { Residual } \\
\text { cortisol }\end{array}$ & $\begin{array}{c}\text { Predni- } \\
\text { solone }\end{array}$ & $\begin{array}{c}20 \beta \text {-Hydroxy- } \\
\text { cortisol }\end{array}$ & $\begin{array}{c}20 \beta \text {-Hydroxy- } \\
\text { prednisolone }\end{array}$ \\
\hline 6 & 4,221 & 640 & - & - \\
12 & 3,100 & 1,771 & - & - \\
18 & 2,363 & 2,495 & - & - \\
24 & 2,255 & 2,355 & 121 & 116 \\
30 & 2,014 & 1,837 & 390 & 596 \\
48 & 1,931 & 1,024 & 516 & 1,371 \\
\hline
\end{tabular}

\section{Convertibility of prednisolone in the presence of reduced glutathione}

In this experiment it was intended to investigate the role of reduced glutathione on the transformation of prednisolone with the experimental organism. As can be seen from Table 3, prednisolone was transformed regularly to $20 \beta$-hydroxyprednisolone. However, the transformation rate was particularly accelerated between 9-12 $\mathrm{hr}$ of fermentation.

Table 3. Transformation of prednisolone $(3,000 \mu \mathrm{g} / 30 \mathrm{ml}$ medium) with $B$. cereus in the presence of reduced glutathione ( $2 \mathrm{mg} / 30 \mathrm{ml}$ medium).

\begin{tabular}{ccc}
\hline $\begin{array}{c}\text { Transformation } \\
\text { period }\end{array}$ & \multicolumn{2}{c}{ Transformation mixture $(\mu \mathrm{g} /$ culture $)$} \\
\cline { 2 - 3 }$(\mathrm{hr})$ & $\begin{array}{c}\text { Residual } \\
\text { prednisolone }\end{array}$ & $\begin{array}{c}20 \beta \text {-Hydroxy- } \\
\text { prednisolone }\end{array}$ \\
\hline 3 & 2,594 & traces \\
6 & 2,225 & 395 \\
9 & 1,859 & 1,026 \\
12 & traces & 2,685 \\
\hline
\end{tabular}

\section{Effect of some steroid inducers}

This investigation was devoted to study the effect of some $\mathrm{C}_{19}$ and $\mathrm{C}_{21}$ steroids as well as cholesterol as inducers of the $\Delta^{1}$-dehydrogenase system of the experimental organism.

This was conducted by growing the experimental organism on aliquots of the basal medium for $24 \mathrm{hr}$, after which the steroid inducer $(2 \mathrm{mg} / 50 \mathrm{ml}$ medium $)$ to be tested was added and the induction period lasted for $10 \mathrm{hr}$. Thereafter, the induced cells were collected, and washed with $0.5 \% \mathrm{NaCl}$ solution and then with distilled water under aseptic conditions. The washed cells were then transferred to aliquots of the basal medium to which cortisol ( $5 \mathrm{mg} / 50 \mathrm{ml}$ medium) was added and transformation period was continued for another $24 \mathrm{hr}$.

The results of this study are given in Table 4. The formation of prednisolone 
was accelerated when the cells were induced with progesterone, $17 \alpha$-hydroxyprogesterone, and 21-hydroxyprogesterone. A better yield of prednisolone was however obtained in the case of $\Delta^{1}$-dehydroprogesterone. Under the latter experimental condition, the amount of $20 \beta$-hydroxycortisol was decreased. Induction of $\Delta^{1}$-dehydrogenation and repression of the 20 -keto reduction reaction of cortisol were also observed with $17 \alpha, 21$-dihydroxyprogesterone and $11 \alpha, 17 \alpha, 21$-trihydroxyprogesterone. In contrast, both enzymic reactions were markedly inactivated in the case of treatment with $11 \alpha$-hydroxyprogesterone.

Table 4. Transformation of cortisol $(5,000 \mu \mathrm{g} / 50 \mathrm{ml}$ medium) with $B$. cereus previously treated with different steroid inducers.

\begin{tabular}{lccc}
\hline & \multicolumn{2}{c}{ Transformation mixture $(\mu \mathrm{g} /$ culture $)$} \\
\cline { 2 - 4 } \multicolumn{1}{c}{ Steroid inducer } & $\begin{array}{c}\text { Residual } \\
\text { cortisol }\end{array}$ & $\begin{array}{c}\text { Predni- } \\
\text { solone }\end{array}$ & $\begin{array}{c}20 \beta \text {-Hydroxy- } \\
\text { cortisol }\end{array}$ \\
\hline Basal medium (control) & 3,435 & 1,082 & 341 \\
Progesterone & 3,443 & 1,151 & 257 \\
$11 \alpha$-Hydroxyprogesterone & 4,249 & 537 & 93 \\
$17 \alpha$-Hydroxyprogesterone & 3,422 & 1,175 & 263 \\
21-Hydroxyprogesterone & 3,400 & 1,242 & 204 \\
$J^{1}$-Dehydroprogesterone & 3,230 & 1,438 & 211 \\
$17 \alpha, 21$-Dihydroprogesterone & 3,502 & 1,163 & 207 \\
$11 \alpha, 17 \alpha, 21$-Trihydroxyprogesterone & 3,514 & 1,116 & 232 \\
$\Delta^{4}$-Androstenedione & 3,531 & 879 & 464 \\
$J^{1,4}$-Androstadienedione & 2,820 & 1,649 & 385 \\
Testosterone & 3,805 & 885 & 183 \\
$\Delta^{1}$-Dehydrotestosterone & 3,346 & 1,327 & 196 \\
Cholesterol & 3,002 & 1,290 & 354 \\
\hline
\end{tabular}

Concerning the effect of tested $\mathrm{C}_{19}$ steroids, the formation of $20 \beta$-hydroxycortisol was induced by androstenedione. In this case, prednisolone was produced in a relatively low yield compared with the control. On the other hand, $\Delta^{1}$-dehydrogenation reaction was greatly induced in the case of $\Delta^{1,4}$-androstadienedione treatment. Similarly, $\Delta^{1}$-dehydrotestosterone appreciably induced prednisolone formation.

Induction of the cells with cholesterol exerted no effect on the formation of $20 \beta$-hydroxycortisol, although it caused the formation of a relatively higher amount of prednisolone. In addition, two other metabolites of non-steroid nature were detected in this case. In order to assess whether these two metabolites were formed directly from cortisol or were further metabolites of $20 \beta$-hydroxycortisol and/or prednisolone, the latter two products were independently used as substrates to be acted upon by cholesterol-pretreated cells. Transformation products were assayed after 24-hr fermentation. It was found that both compounds remained unchanged. These results may indicate that the newly detected 
two metabolites were formed from cortisol.

Effect of some enzyme inhibitors

The results presented in Table 5 indicate that the formation of prednisolone and $20 \beta$-hydroxycortisol was noticeably enhanced by the addition of azide and in particular cyanide to the basal medium. Besides formation of these two transformation products, $20 \beta$-hydroxyprednisolone was also formed.

Table 5. Transformation of cortisol $(5,000 \mu \mathrm{g} / 50 \mathrm{ml}$ medium $)$

with $B$. cereus as influenced by the addition of some enzyme inhibitors to the basal medium.

\begin{tabular}{lcccc}
\hline \multicolumn{1}{c}{ Conditions } & $\begin{array}{c}\text { Residual } \\
\text { cortisol }\end{array}$ & $\begin{array}{c}\text { predni- } \\
\text { solone }\end{array}$ & $\begin{array}{c}20 \beta- \\
\text { Hydroxy- } \\
\text { cortisol }\end{array}$ & $\begin{array}{c}\text { 20ß-Hydro- } \\
\text { xyprednisolone }\end{array}$ \\
\hline Basal medium (control) & 3,475 & 939 & 398 & - \\
Sodium azide & 2,734 & 1,246 & 510 & 372 \\
Sodium cyanide & 2,250 & 1,459 & 714 & 427 \\
Iodoacetate & 2,126 & 1,582 & 169 & - \\
\hline
\end{tabular}

The tested enzyme inhibitors were individually added $(0.5 \mathrm{mg} / 50 \mathrm{ml}$ medium $)$ to the culture medium at the time of cortisol addition.

Transformation period: $24 \mathrm{hr}$.

A different pattern of cortisol bioconversion was observed with iodoacetate. By the addition of iodoacetate, the $\Delta^{1}$-dehydrogenation reaction was markedly activated, but the 20-keto reduction reaction of cortisol was noticeably inhibited. Moreover, 20 $\beta$-hydroxyprednisolone was not formed on iodoacetate treatment.

\section{DISCUSSION}

In a previous work (12), we investigated the mechanism of cortisol transformation with the experimental organism (B. cereus). In separate mechanisms, cortisol transformed to prednisolone and $20 \beta$-hydroxycortisol through the action of 1,2dehydrogenase and 20-keto reductase systems, respectively. The latter reaction is reversed (i.e., 20 $\beta$-hydroxycortisol is oxidized back to cortisol) at certain stages of the reaction sequence. Such activities stimulated us to investigate the effect of some redox agents on the convertibility of cortisol with this organism. Safranin T appeared to be inert. This may be due to permeability difficulties for this azo dye to reach the appropriate sites of the enzymic reactions involved. It was previously reported that Safranin $\mathrm{T}$ did not affect the interconversion of $11 \alpha$-hydroxyprogesterone to $11 \alpha$-hydroxyallopregnane with Rhizopus nigricans (13).

An outstanding increase in the rate of prednisolone formation was observed when oxidized glutathione (GSSG) was added to the fermentation medium. However, a small increase of prednisolone yield was found with Methylene Blue, 2,6-dichlorophenol-indophenol, and 8-hydroxyquinoline. SiH and BeNNETT (14) 
studied the introduction of double bonds into the 1-2 and 4-5 positions of steroids possessing either $5 \alpha$ - or $5 \beta$-pregnane nucleus by cell-free extracts of Nocardia sp., in the presence of some redox agents. They found that phanazine methosulfate acted as a better electron acceptor than potassium ferricyanide, Methylene Blue, or 2,6-dichlorophenol-indophenol. Similarly, the $\Delta^{1}$-dehydrogenation reaction of cortisol with $B$. sphaericus was highly accelerated in the presence of substances with a quinone structure (15).

Emphasis has been laid as far as possible on investigation of the role of GSSG which not only highly accelerated the enzymic 1,2-dehydrogenation of cortisol but also stimulated the formation of $20 \beta$-hydroxyprednisolone. The 1,2-dehydrogenation modification was found to be the only enzymic reaction which predominated during the early phase of the transformation process (6 to $18 \mathrm{hr}$ ). Under these experimental conditions, GSSG seems to act as an efficient oxidizing agent in concert with the $\Delta^{1}$-dehydrogenase system produced by the experimental organism (1):

$$
\text { Cortisol }+ \text { GSSG } \stackrel{\Delta^{1} \text {-dehydrogenase }}{\longrightarrow} \text { Prednisolone }+2 \mathrm{GSH}
$$

It was found that the reduction of the 20-keto group of cortisol and prednisolone was markedly stimulated at the later phase of transformation (18 to $24 \mathrm{hr}$ ). Such findings led to a speculation that, at least part of the reason for the activation of these reduction reactions may be due to the presence of the reduced glutathione (GSH), resulting from the oxidation of cortisol in the presence of GSSG (1). However, prednisolone appeared to be preferentially reduced to $20 \beta$-hydroxy derivative in a relatively higher rate than the reduction of cortisol at the corresponding position (2 and 3):

$$
\begin{array}{r}
\text { Prednisolone }+ \text { GSH } \stackrel{\text { 20-keto reductase }}{\longrightarrow} 20 \beta \text {-hydroxyprednisolone } \\
+ \text { GSSG }
\end{array}
$$

Whether glutathione acts as an enzyme activator or participates as a hydrogen acceptor for the hydrogenase system has to be elucidated by further investigation. Besides its general role as an enzyme activator, glutathione (GSH) has the specific function as a cofactor of many dehydrogenases $(16,17)$.

The view that the reduction of the 20-keto group of prednisolone may be activated in the presence of GSH was further substantiated by the study on the conversion of prednisolone with the experimental organism in the presence of GSH. Its result showed that prednisolone was transformed almost quantitatively to $20 \beta$ hydroxyprednisolone. Such reaction failed to take place in the absence of GSH(12). The successful conversion of prednisolone to $20 \beta$-hydroxy derivative, together with the finding that the amount of the prednisolone formed gradually decreased with 
subsequent increase in the concentration of $20 \beta$-hydroxyprednisolone, may also confirm that the latter product is formed as a result of secondary enzymic reaction on the formed prednisolone.

In accordance with the findings of MURRAY and SEBEK (18) and of LIDA et al. (19), the $\Delta^{1}$-dehydrogenation reaction was markedly induced by $\Delta^{1}$-dehydroprogesterone, and $\Delta^{1,4}$-androstadienedione. In addition, pretreatment of the cells with some other $\mathrm{C}_{19}$ and $\mathrm{C}_{21}$ steroids also exerted a stimulatory action on the formation of prednisolone.

Besides formation of prednisolone and 20 $\beta$-hydroxycortisol, two other metabolites of non-steroid nature were detected when cortisol was metabolized by cells pretreated with cholesterol. These two metabolites were not detected when prednisolone and $20 \beta$-hydroxycortisol were used as substrates. Thus, they may be formed directly from cortisol. The possibility of microbiological degradation of cortisol into non-steroidal products, e.g., $\beta$-seco-9-keto-phenolic derivative had been previously reported (20).

The enzymic 20-keto reduction reaction of cortisol was noticeably promoted in the presence of azide and cyanide. Reduction of the 20-keto group of prednisolone was also achieved under these conditions. It could be assumed that azide and cyanide, known inhibitors of cytochrome oxidases, slowed down the terminal electron transport system, causing accumulation of reduced nicotinamide adenine dinucleotide required for the reduction of the keto group of steroids $(21,22)$.

The $\Delta^{1}$-dehydrogenation reaction of cortisol was also activated with cyanide and azide. These results are in harmony with the report by ATsushi (23) that the formation of prednisolone was stimulated ( $83 \%$ yield) when sodium azide was added to the culture medium of $B$. brevifaciens. The finding that the $\Delta^{1}$-dehydrogenation of cortisol is not inhibited by azide and cyanide suggests that cytochrome oxidase is not involved in this reaction.

The addition of iodoacetate to the fermentation medium repressed the formation of $20 \beta$-hydroxycortisol. Furthermore, 20 $\beta$-hydroxyprednisolone did not form under these conditions. In contrast, prednisolone was accumulated in a high yield in the case of iodoacetate treatment. The repression of the reduction in the presence of iodoacetate may be attributed to the inhibition of nicotinamide adenine dinucleotide-linked dehydrogenases. Such enzymes require -SH group for activity $(24,25)$.

\section{REFERENCES}

1) J. J. Bunim, M. M. Pechet, and A. T. Bollet, J. Am. Med. Assoc., 157, 311 (1955).

2) D. H. Peterson, In Biochemistry of Industrial Microorganisms, ed. by RaINBow and Rose, Academic Press, London and New York (1963), Chapt. 10, p. 537.

3) W. Charney and H. L. Herzog, Microbial Transformation of Steroids, A Hand Book, Academic Press, London and New York (1967).

4) P. Talalay, Annu. Rev. Biochem., 34, 347 (1965).

5) C. J. Sir, and H. W. Whitrock, Annu. Rev. Biochem., 37, 661 (1968). 
6) A. H. El-RefaI, L. A. R. Sallam, and N. Naim, Giorn. Microbiol. (Italy), (1974).

7) A. H. El-Refai, L. A. R. Sallam, and N. Naim, Rev. Latinoam. Microbiol., 16, 183 (1974).

8) L. A. R. Sallam, A. H. El-Refai, and N. Naim, Acta Med. Biol. Germ., 34, 21 (1975).

9) L. A. R. Sallam, A. H. El-Refai, and I. A. El-Kady, J. Gen. Appl. Microbiol., 15, 309 (1969).

10) L. A. R. Sallam, A. H. El-Refai, and I. A. El-Kady, J. Gen. Appl. Microbiol., 20, 117 (1974).

11) A. Mizsei, and A. SzABo, J. Biochem. Microbiol. Technol. Eng., 3, 119 (1961).

12) L. A. R. Sallam, A. H. El-Refai, and N. Naim, Ann. Microbiol., 23, 173 (1973).

13) L. A. R. Sallam, A. H. El-Refai, and I. A. El-Kady, J. Gen. Appl. Microbiol., 16, 409 (1970).

14) C. J. Sir, and R. BennetT, Biochim. Biophys. Acta, 38, 378 (1960).

15) V. Stevanovic, M. Hayano, and R. I. Dorfman, Biochim. Biophys. Acta, 71, 429 (1963).

16) P. C. Jocelyn, Glutathione, Biochemical Society No.17, Cambridge University Press (1959).

17) B. ManNervik, and G. NiseE, Arch. Biochem. Biophys., 134, 90 (1969).

18) H. C. Murray, and O. K. SebeK, U. S. Patent 2,902,419, (Sept. 1, 1959).

19) M. Lida, J. D. Tovnsley, M. Hayano, and H. J. Brodie, Steroids, Suppl., 1, 159 (1965).

20) A. CAPEK, O. Hanc, B. KaKac, and M. TADra, Folia Microbiol., 7, 175 (1962).

21) H. J. Hubener, F. G. Sahtho, J. Schmidt-Thom, C. Nesemann, and R. Junke, Biochim. Biophys. Acta, 35, 270 (1959).

22) J. Schmidt-Thome, G. Nesemann, H. J. Hubener, and I. Alester, Biochem. Z., 336, 322 (1962).

23) N. Atsushi, Jpn. Patent 25,649/1967, (Appl. June, 1964).

24) P. Talalay, and P. I. Marcus, J. Biol. Chem., 218, 677 (1956).

25) F. M. Tomkins, Recent Progr. Hormone Res., 12, 125 (1956). 